\title{
Talents Cultivation Tactics of "Three-Three-System" Mode in Major Related to Aquatic and Fishery
}

\author{
Hailong $\mathrm{Xu}^{1,2,3}$, Dongqing Bai ${ }^{1,2,3,{ }^{* *}}, \mathrm{Li} \mathrm{Li}^{1, *}$, Zhaojun Tan ${ }^{1}$, Qingkui Wang ${ }^{1,2,3}$, Jinhui Sun ${ }^{1,2,3}$, \\ Xiuting Qiao ${ }^{1,2,3}$ \\ ${ }^{1}$ Department of Fishery Sciences, Tianjin Agricultural University, 22 Jinjing Road, Tianjin 300384, \\ P. R. China \\ ${ }^{2}$ National Demonstration Center for Experimental Aqua-ecology and Aquaculture Education \\ (Tianjin Agriculture University), 22 Jinjing Road, Tianjin 300384, P. R. China \\ ${ }^{3}$ Tianjin Key Laboratory of Aqua-ecology and Aquaculture, 22 Jinjing Road, Tianjin 300384, P. R. \\ China \\ *Hailong Xu, Li Li should be considered co-first authors \\ **Corresponding author
}

Keywords: Aquatic and Fishery, Talents Cultivation Tactics, Three-Three-System.

Abstract: Aquatic fishery plays a very important role in national economic development, and the supplement of high-quality talents is the key to realizing industrial transformation and maintaining rapid development. There are many shortcomings in the cultivation of traditional aquatic talents under new economic and social environment. This paper analyzes the characteristics of "Three-Three System" talents cultivation mode and proposes the strategy of implementing the "Three-Three System" cultivation model in training aquatic talents process, it aims to provide reference for promoting the development of aquatic profession.

\section{Introduction}

On April 7, 2016, the "China Higher Education Quality Report" was released by the Ministry of Education of the People's Republic of China. The "Report" pointed that China higher education has achieved leaping development since 2000. In 2015, the number of students in university reached 37 million, ranked the first in the world; 2852 colleges and universities, ranked second in the world; admission students account for $40 \%$ of college entrance examination students, which is higher than the global average level. The rapid development of China higher education provides decisive support of talent and intelligence to the historical changes in China social economy.

The report of the Eighteenth National Congress of the Communist Party of China pointed out that higher education should "Adhere to education and serve the socialist modernization, serve the people, combine with productive labor and social practice, and cultivate socialist builders and successors who are fully developed in moral, intelligence, sports, aesthetics and labor." However, the adaptability of higher education has shown a significant lag with the rapid development of the economy and society. It is generally believed that there is a "appreciating science and technology, neglecting humanity" in China's higher education, and the cultivation of students' comprehensive 
quality is seriously inadequate. The concept of "taking the school as the main body, taking the students as the basis, and teaching based on the learning effect of students" has not been fully rooted in the hearts of the educational workers. The spread of advanced international concept is relatively slow, and the advanced concepts of "student-centered", "result-oriented education" and "cultivating quality culture" which are internationally common have not been given due attention. There are a series of problems such as insufficient participation of social forces and small correlation between employment and the majors.

China is a traditional agricultural country, and aquatic fisheries are an important component of the national economy. According to the statistics, in 2015, the national total output of aquatic products was 6699.65 million tons, the total economic output value of fishery in the whole society was 22019.94 billion yuan, and the per capita net income of the fishermen was 14,426.26 yuan. At the same time, the aquaculture has made outstanding contributions to the oath of the sea, alleviating food shortages, stabilizing the society, and increasing the income of residents.

According to the "Undergraduate Professional Catalogue of General Colleges and Universities" issued by the Ministry of Education, the undergraduate majors in aquaculture included aquaculture, marine fishery science and technology and aquarium science and technology which are the important part of higher education in China and the important foundation for supporting the development of aquatic, fisheries and some related industries. The traditional cultivation of aquatic talents starts from the "Discipline-Based" model and considers the courses development with a complete disciplinary system as the start point, and it emphasizes the integrity, systematic and strictness of theoretical knowledge, lacks the grasp of social needs, cannot adapt to the needs of the market and society. With the rapid development of the economy and society, the talents demand in aquatic and fishery has seen a significant shift, and innovative, practical, and specialized talents have become a demand.

\section{Problems in the Traditional Aquatic Education Model}

Training professionals is the only goal in the traditional aquatic talent cultivation model, courses setting is based on the teaching professional skills, the proportion of compulsory courses is too large, and the autonomy and free development space for students are limited. The individualized development of students does not receive enough attention, learning motivation and enthusiasm are weakened, and the potential for independent development is bounded. All students study the same major courses, and the proportion of the total amount of professional courses is larger [1]. The cultivation model does not meet the requirements of talent diversity training, and it enables students to have time to dabble knowledge outside the professional field, leads to humanistic literacy and scientific spirit of students is lacking, the subject vision is not broad enough, the foundation is insufficient, and the innovation ability is not strong. Due to the long-term influence of exam-oriented education, teaching methods over-emphasize knowledge transfer, and innovative thinking training is ignored. Students are accustomed to passively accepting knowledge, trusting authority, books and experience, and lacking the awareness of active understanding and questioning. Students are difficult to propose an innovative solution when they meet problems. Flexibility and plasticity of the teaching management system is insufficient and there is lack of motivation for sustained development. The design of the management system cannot better reflect the concept of "Taking Student Development as the Center", the too rigid teaching management limits the individualized development of students. Teaching reform often relies on top-down administrative drive and lacks an internal driving mechanism, which affects the effectiveness and sustainability of the reform. 


\section{Concept of Undergraduate Talents Cultivation in "Three-Three System"}

The "Three-Three System" Talents Cultivation Model is an important reform of China higher education and talents cultivation, it bases on the principle of "sufficiently guaranteeing independent choice and individuality development of student" and divides the undergraduate cultivation process into three stages included large class cultivation, professional training, multivariate culture, and divides into three development paths contained professional academic, cross composite, employment and entrepreneurship ${ }^{[2]}$. The "Large Class Cultivation Stage" aims to promote the comprehensive improvement of students' humanities and scientific literacy through the implementation of general education, the "Professional Cultivation Stage" focuses on improving professionalism and professional competence of students, the "Diversified Cultivation Stage" focuses on ensuring independent choice of students in three development paths included professional academic, cross compositing, employment and entrepreneurship and lets students have the opportunity to choose their own majors, courses and development paths.

\section{"Three-Three Systems" Implementation Strategy in Aquatic Professional Talents Cultivation}

Providing time to learn independently and personalized development opportunities for students. In order to better providing students with space for study and personal development, we have reformed the cultivation programs of majors in aquaculture, marine fishery science and technology and aquarium science and technology, the main measures are as follows: 1. reduce the total credits that meet the graduation requirements to about 165 , adjust the courses system, reduce the proportion of compulsory courses, and change the restricted course to optional courses; 2. Open mental health, career planning, employment guidance, and entrepreneurship courses, promote the comprehensive development of students [3]; 3. Set three directions in every major, students can choose the direction of major according to their personal interests when they enter the third year of university, the three directions of aquaculture major are aquatic animal diseases, aquatic cultivation and nutrition and feed, the three directions of fishery science and technology are resource biology, resource and environment and fisheries management, the three directions of aquarium science and technology are disease, cultivation and unlimited; 4. Implement the undergraduate tutor system, provide professional cognitive internships to help students complete the transition from high school life to university life, make students to understand the major and direction earlier, in more detail and more accurately [4]; 5. For seniors, lectures are given by young and middle-aged teachers with profound academic attainments and active academic ideas to help students understand the academic frontier, develop the ability to independently discover, analyze, and solve problems.

\section{Conclusion}

All kinds of talent cultivation model are based on the premise of serving the economy and personal development. China is a traditional agricultural country, and aquatic fisheries play a very important role in the development of the national economy. In the process of economic and social transformation, aquatic fisheries have meet new challenges and opportunities. Implementation of the "Three-Three System" in aquatic talents cultivation is based on the development characteristics of the aquatic industry under the new situation and the actual demand for talent growth. Only complying with the laws of higher education development, implementing the educational philosophy of "taking school as the foundation and taking students as the core", paying attention to the coordination of thought and values education, professional education and personal development of students can establish the "Three-Three-System" talents cultivation model which follow the goal of higher education talent cultivation, match the individualized development of students, and adapt 
to the needs of the industry.

\section{Acknowledgement}

This research was financially supported by the important project for the education reform of Tianjin Agricultural University (2017-B-02).

\section{References}

[1] Dongqing Bai, Li LI, Hailong Xu, et al. Reform of experiment course system in the major about aquatic and fishery, Education and Teaching Form, 2015,(21):255-256.

[2] Liang Li, Qiu Zhang. Exploration and practice of tutorial system for undergraduate students under the education mode of "Three-Three-System" [J]. Journal of PLA Nanjing Institute of Politics, 2015(6):149-149.

[3] Li LI, Hailong Xu, Dongqing Bai. Constructed the Innovative Education Mode in Marine Fishery Science and Technology Major. Education and Vocation, 2015(16):89-91.

[4] Hailong Xu, Dongqing Bai, Li LI. The Reform of Practice Teaching in Marine Fishery Science and Technology Major [A]. 3rd International Conference on Education and Social Development[C], Pennsylvania: DES tech Publications, 2017, 480-483. 